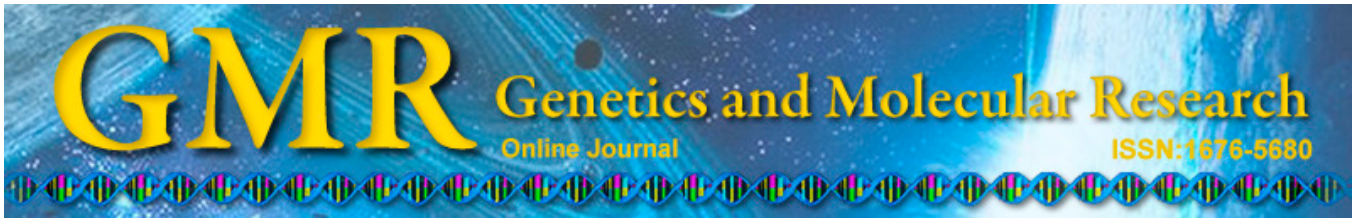

\title{
Effect of pinacidil on rat ventricular myocytes during transient hypoxia and reperfusion
}

\author{
X.Y. Dong and F. Zhu \\ Medical College, Wuhan University, China \\ Corresponding author: F. Zhu \\ E-mail: fenzhucn@126.com \\ Genet. Mol. Res. 13 (4): 8197-8208 (2014) \\ Received April 26, 2013 \\ Accepted January 21, 2014 \\ Published October 8, 2014 \\ DOI http://dx.doi.org/10.4238/2014.October.8.1
}

Department of Cardiology, Wuhan Third Hospital \& Affiliated Tongren Hospital,

\begin{abstract}
The aim of this study was to evaluate the cardioprotective effect of pinacidil postconditioning on rat hearts with transient hypoxia and reperfusion. An acute myocardial anoxia-reperfusion rat model was created by ligating coronary arteries for $10 \mathrm{~min}$ and subsequent reperfusion for $60 \mathrm{~min}$. Twenty-four rats in 4 groups received different treatments: normal hearts as control $(\mathrm{N}=6)$, anoxia-reperfusion $(A / R)$ only $(N=6)$, pinacidil postconditioning $(N=6)$, and pinacidil plus adenosine triphosphate-sensitive potassium channel inhibitors (glibenclamide) $(\mathrm{N}=6)$. The kinetic parameters and electrophysiological properties, including early apoptosis protein expression changes of Bax, Bcl-2, and FN were examined using the isolated perfusion and patch-clamp technique and immunohistochemistry. The left ventricular systolic pressure and maximum - $d p / d t$ in $\mathrm{A} / \mathrm{R}$ groups were significantly higher than those in the control group $(\mathrm{P}<0.05)$. The left ventricular developing pressure, maximum $+d p / d t$, and heart rate in the $\mathrm{A} / \mathrm{R}$ group were slightly decreased. The pinacidil-postconditioned group has better cardiac function recovery after ischemia/reperfusion than the $\mathrm{A} / \mathrm{R}$ group $(\mathrm{P}<0.01)$. In addition, using the patch-clamp technique, the mean open time and conductance values are significantly higher in the pinacidil postconditioning group, compared with those in the $A / R$ group. The
\end{abstract}


expression of apoptosis proteins (Bax, FN) increased during $\mathrm{A} / \mathrm{R}$, while Bcl-2 protein expression decreased. A significant difference was found in the pinacidil treatment group relative to the $\mathrm{A} / \mathrm{R}$ group. Pinacidil postconditioning can exert cardioprotective effects on $\mathrm{A} / \mathrm{R}$-injured rat hearts, which may indicate a potential application of pinacidil postconditioning to protect $\mathrm{A} / \mathrm{R}$-injured hearts.

Key words: Pinacidil; Transient hypoxia-reperfusion; Patch-clamp

\section{INTRODUCTION}

Since the first discovery of adenosine triphosphate-sensitive potassium $\left(\mathrm{K}_{\mathrm{ATP}}\right)$ channels in Guinea pig ventricular myocytes that were isolated by Noma in 1983, accumulating studies have shown that similar types of potassium channels are present in many other tissues, including vascular smooth muscle cells, skeletal muscle cells, and neuronal cells. In cardiac muscle, the $\mathrm{K}_{\text {ATP }}$ channel is closed under physiological conditions, but it is opened when metabolic inhibition occurs by myocardial ischemia (Holmuhamedov et al., 1999; Vanden Hoek et al., 2000; Beguin et al., 2005; Zhou et al., 2005). Our previous studies showed that transient hypoxia and reperfusion (THR) could protect the heart against ischemia/reperfusion injury. Until now, most studies on $\mathrm{K}_{\text {ATP }}$ channel cardioprotection were carried out in experimental animals. However, the effect of THR on the heart is not well defined (Zhu et al., 2003). The objective of this study was to determine whether $\mathrm{K}_{\text {ATP }}$ channels confer cardioprotection during reperfusion.

Therefore, in this study, we used pinacidil, a $\mathrm{K}_{\text {ATP }}$ channel opener. We assessed the cardioprotection of intravenous administration of pinacidil on the THR phenomenon. This phenomenon is associated with the kinetics of the $\mathrm{K}_{\text {ATP }}$ channels in rat ventricular myocytes and electrophysiological properties of the $\mathrm{K}_{\text {ATP }}$ channels in rat ventricular myocytes in anoxiareperfusion (A/R). Our results may reinforce the understanding of the contribution of the $\mathrm{K}_{\text {ATP }}$ channels to the functional activities of hearts.

\section{MATERIAL AND METHODS}

\section{Materials}

Male adult Wistar rats (250-350 g) were purchased from the Prevention Science Institute in Hu Bei Province. We used a Langendorff retrograde configuration and an EPC-9 amplifier.

\section{Solutions}

Isolated hearts were perfused by a Krebs-Henseleit buffer (K-H solution) containing $118.7 \mathrm{mM} \mathrm{NaCl}, 4.7 \mathrm{mM} \mathrm{KCl}, 1.2 \mathrm{mM} \mathrm{MgSO}_{4}, 0.95 \mathrm{mM} \mathrm{KH}_{2} \mathrm{PO}_{4}, 28.0 \mathrm{mM} \mathrm{NaHCO}, 1.3$ $\mathrm{mM} \mathrm{CaCl}$, and $10.0 \mathrm{mM}$ glucose, with the $\mathrm{pH}$ adjusted to 7.4, and Kerb solution containing $125 \mathrm{mM} \mathrm{NaCl}, 5.9 \mathrm{mM} \mathrm{KCl}, 1.2 \mathrm{mM} \mathrm{MgCl}, 1.2 \mathrm{mM} \mathrm{NaHPO}_{4}, 10 \mathrm{mM}$ 2-[4-(2-hydroxyethyl) piperazin-1-yl] ethanesulfonic acid (HEPES), and $11.5 \mathrm{mM}$ glucose, with the $\mathrm{pH}$ adjusted to 7.2. Patch pipettes were filled with a solution including $140 \mathrm{mM} \mathrm{KCl}, 1.48 \mathrm{mM} \mathrm{CaCl}_{2}, 10 \mathrm{mM}$ 
HEPES, $3 \mathrm{mM}$ ethylene glycol tetraacetic acid (EGTA), with the pH adjusted to 7.3. In the experiment, we applied solutions containing $140 \mathrm{mM} \mathrm{KCl}, 10 \mathrm{mM}$ HEPES, and $2 \mathrm{mM}$ EGTA to single cells with the aid of a hand-controlled perfusion system. In another experiment, drug solutions ( $20 \mu \mathrm{M}$ pinacidil and $10 \mu \mathrm{M}$ glibenclamide) were added to the cells while exchanging the bathing solutions in the chamber at a flow rate of $1.4 \mathrm{~mL} / \mathrm{min}$. All reagents were purchased from Sigma Company.

\section{Experimental protocols}

Twenty-four adult male rats were randomly divided into four groups and subjected to the following treatments: control group, hearts underwent a 60-min perfusion; A/R group, hearts underwent a 10-min stopping-perfusion similar to anoxia/ischemia followed by a 60-min reperfusion; treatment group (pinacidil $+\mathrm{A} / \mathrm{R}$ ), hearts were subjected to a 5-min anoxia and then were treated with pinacidil $(20 \mu \mathrm{M})$ perfusion for $10 \mathrm{~min}$, followed by a 60 -min reperfusion, which made the total perfusion time the same as the other two groups; pinacidil + glibenclamide $+\mathrm{A} / \mathrm{R}$ group, hearts were subjected to a 5-min anoxia and then were treated with pinacidil $(20 \mu \mathrm{M})$ perfusion for $10 \mathrm{~min}$, followed with glibenclamide with reperfusion for $60 \mathrm{~min}$.

\section{Animal model of acute myocardial anoxia/ischemia and reperfusion}

Cardiac myocytes were isolated from the male adult Wistar rats (250-350 g). Heparin $(200 \mathrm{IU} / \mathrm{kg}$ ) was administered intraperitoneally. After animals were anesthetized with sodium pentobarbital (30 mg/kg by intraperitoneal injection), the hearts were quickly removed and rinsed in K-H solution for cannulation through the aorta via a Langendorff retrograde perfusion. Excess blood in heart chambers was washed out at $37^{\circ} \mathrm{C}$ with $\mathrm{K}-\mathrm{H}$ solution (gassed with $5 \% \mathrm{CO}_{2}$ and $95 \% \mathrm{O}_{2}$ ).

\section{Cardiac function and kinetic parameter measurements}

The isolated hearts were perfused in the Langendorff apparatus. After 10 min of stabilization, the heart was subjected to $30 \mathrm{~min}$ of global no-flow ischemia, which was followed by 60 min of reperfusion. A water-filled latex balloon was inserted into the left ventricle through the left atrium, and the pressure in the balloon was set at about $8 \mathrm{mmHg}$ during the initial equilibration. The balloon was connected to a pressure transducer via a rigid fluid-filled catheter to measure the ventricular pressure. The cardiac function activity was recorded 5 min before ischemia and 1, 5, 10, 20,30, and 60 min during reperfusion. The parameters of cardiac function included left ventricular developing pressure (LVDP), left ventricular systolic pressure (LVSP), and maximal positive ( $\left.+\mathrm{LV} d p / d t_{\max }\right)$ and negative $\left(-\mathrm{LV} d p / d t_{\max }\right)$ velocity of left ventricular pressure.

\section{Immunohistochemistry}

The entire heart was quickly excised, and the atria and fatty tissues were removed. The ventricles of the rat heart were rinsed in excess $10 \%$ paraformaldehyde for $48 \mathrm{~h}$ at room temperature. After being fixed, the ventricles were embedded in paraffin and sliced transversely into sections that were about $2 \mathrm{~mm}$ thick. The sections were collected from four dif- 
ferent animal groups. Substance P immunohistochemical staining was used to determine the expression of the apoptosis proteins Bax/Bcl-2 and FN. Images were recorded with a light microscope system. Data were analyzed by histochemical, immunohistochemical, and image analysis techniques (HMIAS-2000).

\section{Cell isolation}

After rats were sacrificed, the hearts were removed and perfused at $37^{\circ} \mathrm{C}$ through the aorta with Kerb solution via a Langendorff retrograde perfusion. Excess blood in the heart chamber was washed out at $37^{\circ} \mathrm{C}$ with oxygenated $\left(100 \% \mathrm{O}_{2}\right)$ Kerb solution. Subsequently, the hearts were perfused with the same solution containing collagenase I $(1 \mathrm{mg} / \mathrm{mL})$ for 30 $\min$. The atria were then removed. The digested ventricle tissue was placed in Kerb solution, and cells were obtained by gentle mechanical agitation. This procedure consistently yielded approximately $80 \%$ rod-shaped $\mathrm{Ca}^{2+}$-tolerant myocytes (Wang and Ashraf, 1999). About $80 \%$ of myocytes had a clear cell boundary and clear stripes in columns that were observed under an inverted microscope. A few such cells appeared to have faster self-discipline contraction early in the perfusion with prolonged perfusion time, and the self-regulation slowed down and stopped contraction. The cell with stripes were chosen in the experimental process because their surface is smooth, short, columnar, and stationary. Calcium-tolerant ventricular myocytes were easily selected (Gok et al., 2006; Gumina et al., 2007).

\section{Electrophysiological measurements}

Cells were bathed at room temperature $\left(25^{\circ} \mathrm{C}\right)$ in Kerb solution. Then, cells were transferred to a recording chamber positioned on the stage of an inverted microscope (OLYMPUS, China). The recording pipettes were pulled from thin-walled borosilicate glass capillaries (Sigma, USA) using a two-stage microelectrode puller (PP-830, Japan), and tips were fire-polished with a microforge (Japan). When filled with pipette solution, their resistance generally ranged between 1 and $10 \mathrm{G} \Omega$. Ion currents were recorded in a cell-attached configuration of the patch-clamp technique by a patch-clamp amplifier (EPC-9, Germany). All potentials were corrected for the liquid junction potential. The signals were displayed on an analog/digital oscilloscope and on a liquid crystal projector (DELL). The data were recorded and analyzed by the pCLAMP 9.0 software.

\section{Statistical analysis}

All values are reported as means \pm standard error of the mean. Comparisons between groups were analyzed with the paired $t$-test. Differences between values were considered to be significant when $\mathrm{P}<0.05$.

\section{RESULTS}

\section{Cardiac function and kinetic parameters}

We determined whether the kinetic parameters such as HR, LVDP, LVSP, + LV $d p /$ $d t_{\max }$, and $-\mathrm{LV} d p / d t_{\max }$ were reflected in myocardial $\mathrm{A} / \mathrm{R}$ in experiment rats. Rat hearts were 
subjected to K-H perfusion in a group, and some rat hearts were subjected to no flow ischemia for $20 \mathrm{~min}$ and reperfusion for $60 \mathrm{~min}$. There were significant differences $(\mathrm{P}<0.01)$ in the kinetic parameters including HR, LVDP, LVSP, and $\pm d p / d t_{\max }$ in the ischemia and reperfusion group. These results demonstrate that $\mathrm{A} / \mathrm{R}$ in rats could increase LVSP, $+d p / d t_{\max }$, and $-d p /$ $d t_{\max }$ markedly, while LVDP and HR were slightly decreased. In contrast, these changes were abolished in the pinacidil group $(\mathrm{N}=6)$ (Table 1 and Figure 1).

Table 1. Comparison in cardiac function parameters $(\mathrm{N}=6)$.

\begin{tabular}{lccc}
\hline Group & Control & $\mathrm{A} / \mathrm{R}$ & Pinacidil \\
\hline $\mathrm{HR}(\mathrm{bpm})$ & $178 \pm 58$ & $156 \pm 54^{* *}$ & $230 \pm 89^{* *}$ \\
$+\mathrm{dp} / \mathrm{dt} \max _{\max }(\mathrm{kPa} / \mathrm{s})$ & $151.52 \pm 54.79^{*}$ & $152.11 \pm 90.42^{*}$ & $158.54 \pm 9.69$ \\
$-\mathrm{dp} / \mathrm{dt}$ max $(\mathrm{kPa} / \mathrm{s})$ & $123.06 \pm 10.38^{\#}$ & $120.95 \pm 23.95^{\#}$ & $166.18 \pm 75.07$ \\
LVSP $(\mathrm{kPa})$ & $3.94 \pm 1.32^{\star}$ & $1.99 \pm 0.69$ & $4.11 \pm 1.80^{\Delta}$ \\
LVDP $(\mathrm{kPa})$ & $6.33 \pm 2.54$ & $9.63 \pm 1.9^{*}$ & $7.33 \pm 3.65$ \\
\hline
\end{tabular}

$\mathrm{A} / \mathrm{R}=$ anoxia-reperfusion; $\mathrm{HR}=$ heart rate $+d p / d t$ and $-d p / d t=$ maximal positive and negative velocity; $\mathrm{LVSP}=$ and LVDP $=$ left ventricular systolic and developing pressure. ${ }^{*} \mathrm{P}<0.05,{ }^{*} * \mathrm{P}<0.01$ vs control; ${ }^{*} \mathrm{P}<0.05,{ }^{\#} \mathrm{P}<0.01$ vs pinacidil; ${ }^{\Delta} \mathrm{P}<0.05$ vs $\mathrm{A} / \mathrm{R}$. Compared with the control group, the hypoxia reperfusion group showed a significant effect of heart damage; during reperfusion the recovery of cardiac function was lower than the control group $(\mathrm{P}<$ 0.05). Compared with the hypoxic reperfusion group, the pinacidil treatment group significantly restored cardiac function indexes $(\mathrm{P}<0.01)$.
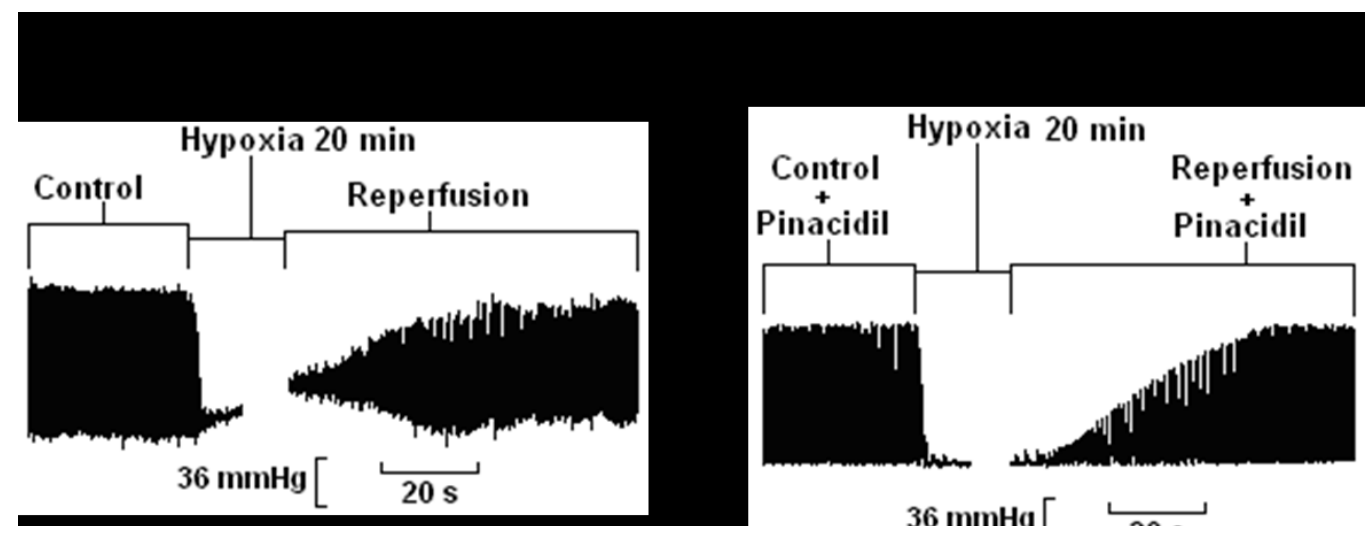

Figure 1. Pretreatment with pinacidil for $10 \mathrm{~min}$ before improving the recovery of kinetic functions after $60 \mathrm{~min}$ of reperfusion. A. A/R group. B. Pinacidil group.

\section{Immunohistochemistry}

As shown in Figure 2, an immunohistological approach was also made to identify the expression of the apoptosis proteins (Bax, Bcl-2, and FN) in rat ventricles. Changes in apoptosis proteins in ischemic-reperfusion myocardium in 24 Wistar rats were studied by histochemical, immunohistochemical, and image analysis techniques. Bax, Bcl-2, and FN expressions were assessed by the optical density (OD) values of apoptosis protein. The results showed that the OD values of $\mathrm{Bcl}-2$ and $\mathrm{FN}$ apoptosis proteins were significantly increased in the $\mathrm{A} / \mathrm{R}$ and pinacidil group $(\mathrm{N}=10)$ (Table 2 and Figures 3-5). 


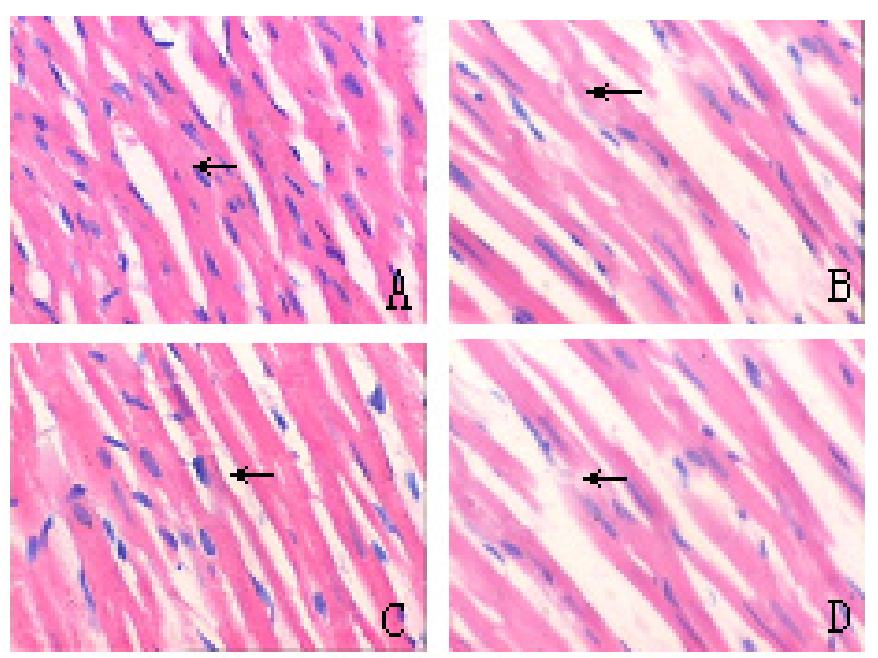

Figure 2. HE histochemistry in the four groups (400X). A. Control. B. A/R. C. Pinacidil. D. Pinacidil+glibenclamide.

Table 2. Comparison of the positive area rates of apoptosis protein.

\begin{tabular}{llccc}
\hline & Control & A/R & Pinacidil & Glibenclamide \\
\hline Bax & $34.08 \pm 1.34$ & $55.33 \pm 1.37^{*}$ & $22.42 \pm 1.08^{*}$ & $51.23 \pm 1.25$ \\
Bcl-2 & $32.08 \pm 1.13^{*}$ & $45.55 \pm 1.13$ & $40.24 \pm 1.84^{*}$ & $39.15 \pm 1.17$ \\
FN & $16.85 \pm 1.02$ & $23.27 \pm 1.58^{* *}$ & $18.35 \pm 0.98^{* *}$ & $22.34 \pm 1.31$ \\
\hline${ }^{\#} \mathrm{P}<0.05$, pinacidil $v s \mathrm{~A} / \mathrm{R} ;{ }^{*} \mathrm{P}<0.01$, control $v s$ pinacidil $* * \mathrm{P}<0.05$, pinacidil $v s \mathrm{~A} / \mathrm{R} . \mathrm{A} / \mathrm{R}=$ anoxia-reperfusion.
\end{tabular}

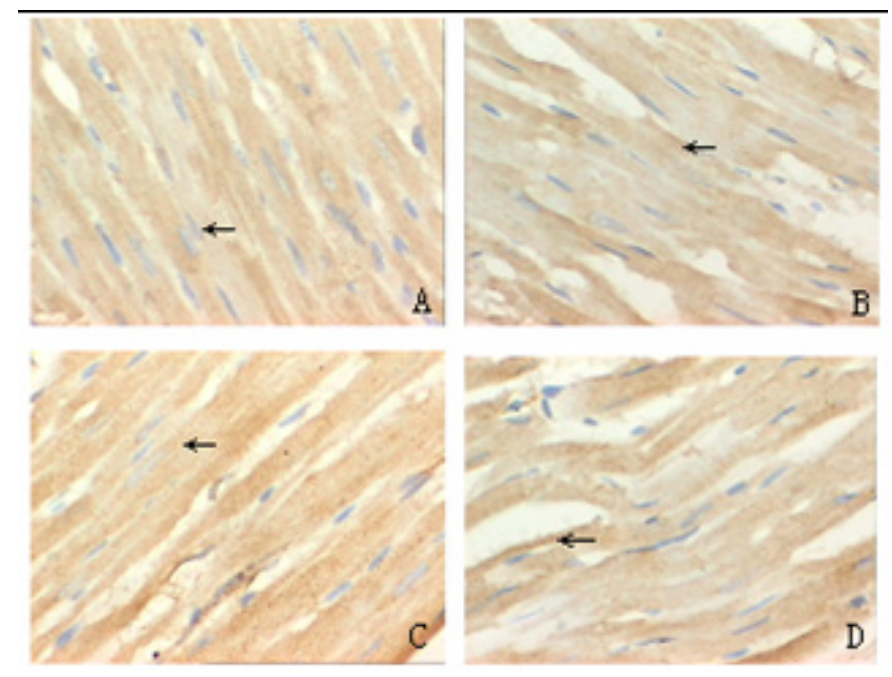

Figure 3. Bax expression levels were not different among the groups. A. Control. B. A/R. C. Pinacidil. D. Pinacidil+ glibenclamide. 

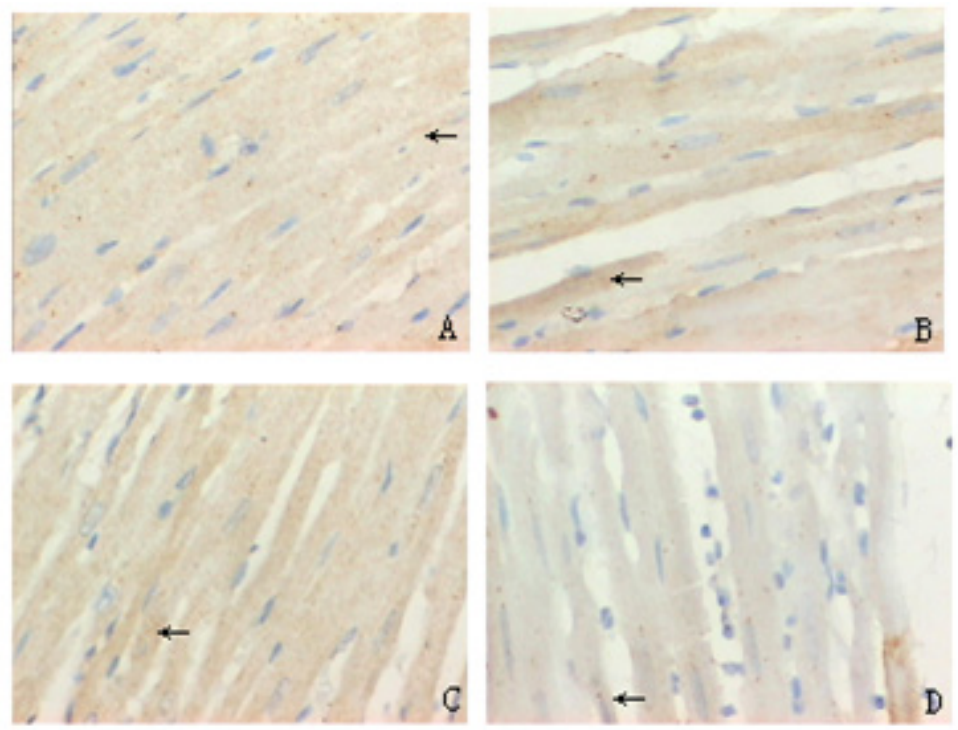

Figure 4. Bcl-2 protein expressions were not different among the groups. A. Control. B. A/R. C. Pinacidil. D. Pinacidil+glibenclamide.
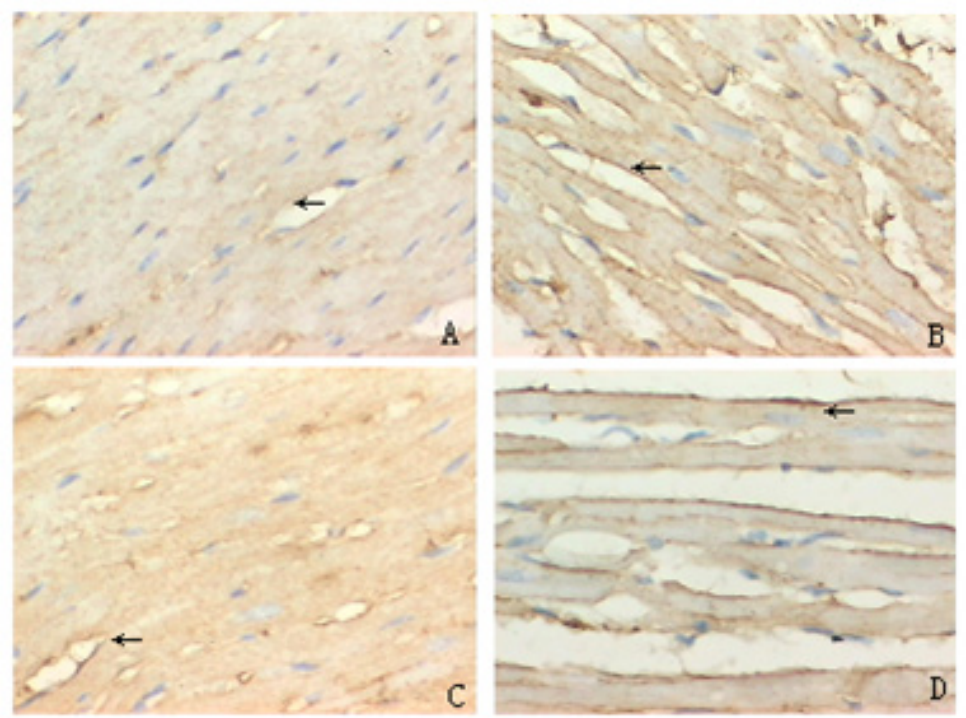

Figure 5. FN protein expressions in the four groups. A. Control. B. A/R. C. Pinacidil. D. Pinacidil+glibenclamide.

\section{Electrophysiological properties}

To investigate the electrophysiological characteristics of normal, ischemic, and reperfused ventricular myocardium in rat, we used computer signal acquisition and processing 
techniques. The superfusion method of ventricular myocardium in a cell-attached configuration recording technique was adopted. In the $\mathrm{K}_{\text {ATP }}$ channel experiments, cells were bathed in $140 \mathrm{mM} \mathrm{K}$. In the cell-attached configuration, the cell was held at different levels of holding potential (i.e., -60 to $+60 \mathrm{mV}$ ) (Figure 6) $(\mathrm{N}=6)$.

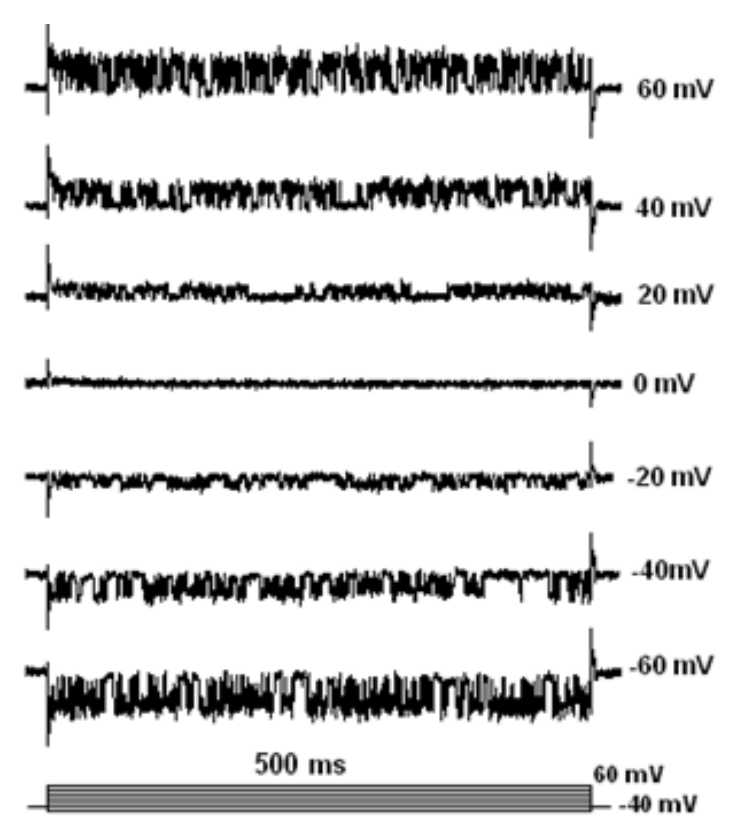

$5 \mathrm{pA} \mid$

$100 \mathrm{~ms}$

Figure 6. Current traces of the $\mathrm{K}_{\text {ATP }}$ channels in isolated rat ventricular myocytes (I/V curves). Cells were held at different membrane potential in cell-attached configuration. Kinetics of $\mathrm{K}_{\text {ATP }}$ channels when holding potential were $60 \mathrm{mV}$ and $-60 \mathrm{mV}$. Single-channel currents recorded from an inside-out patch of a ventricular myocardium at various holding potentials. The line fitted to the data points from $60 \mathrm{mV}$ to $-60 \mathrm{mV}$ gave a slope conductance of $63 \mathrm{pS}$.

We also investigated the effects of pinacidil on the activity of $\mathrm{K}_{\text {ATP }}$ channels. The $\mathrm{K}_{\text {ATP }}$ channel currents occurred in rapid open transitions and brief bursts with a current amplitude of $3.11 \pm 0.21 \mathrm{pA}$ at $-60 \mathrm{mV}(\mathrm{N}=6)$. The single-channel conductance of the control, $\mathrm{A} / \mathrm{R}$ and $\mathrm{A} / \mathrm{R}+$ pinacidil groups was $82.71 \pm 4.05,103.50 \pm 6.82$ and $148.70 \pm 5.84 \mathrm{pS}$, respectively $(\mathrm{N}$ =6) (Figure 7).

\section{Kinetic properties of the $K_{\text {ATP }}$ channel}

To compare the kinetic properties of the four groups, we also analyzed the mean lifetime of channel openings. Open-time histograms that were measured in these cells were as shown. The open-time index data of $\mathrm{K}_{\text {ATP }}$ channels were measured in the $\mathrm{A} / \mathrm{R}$ group $(\tau=2.345)$ and pinacidil group $(\tau=2.628)$ (Figure 8$)$. There was a significant difference in the mean open 
time between these two groups $(2.06 \pm 0.11$ vs $2.35 \pm 0.08 \mathrm{~ms} ; \mathrm{N}=6)$. These changes were more pronounced in the pinacidil group, whereas glibenclamide abolished these changes.

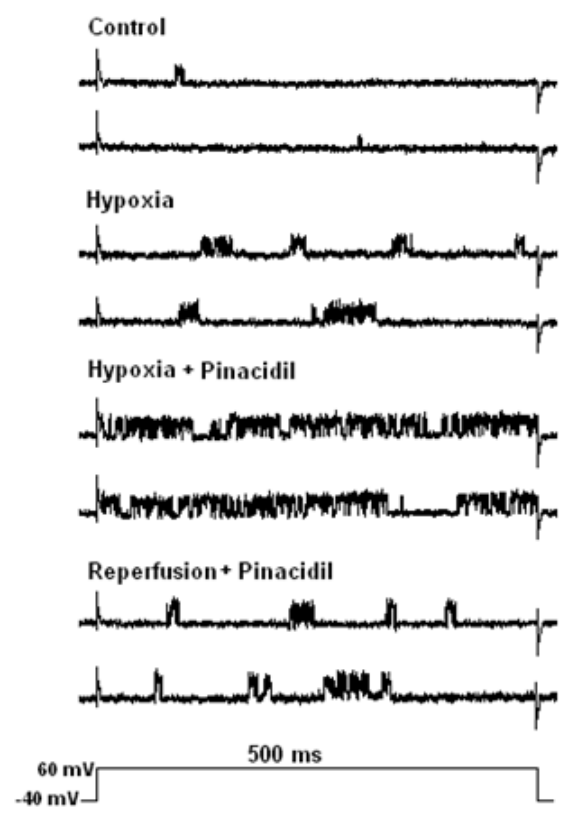

Figure 7. Effects of pinacidil on the activity of $\mathrm{K}_{\mathrm{ATP}}$ channels under hypoxia/reperfusion.
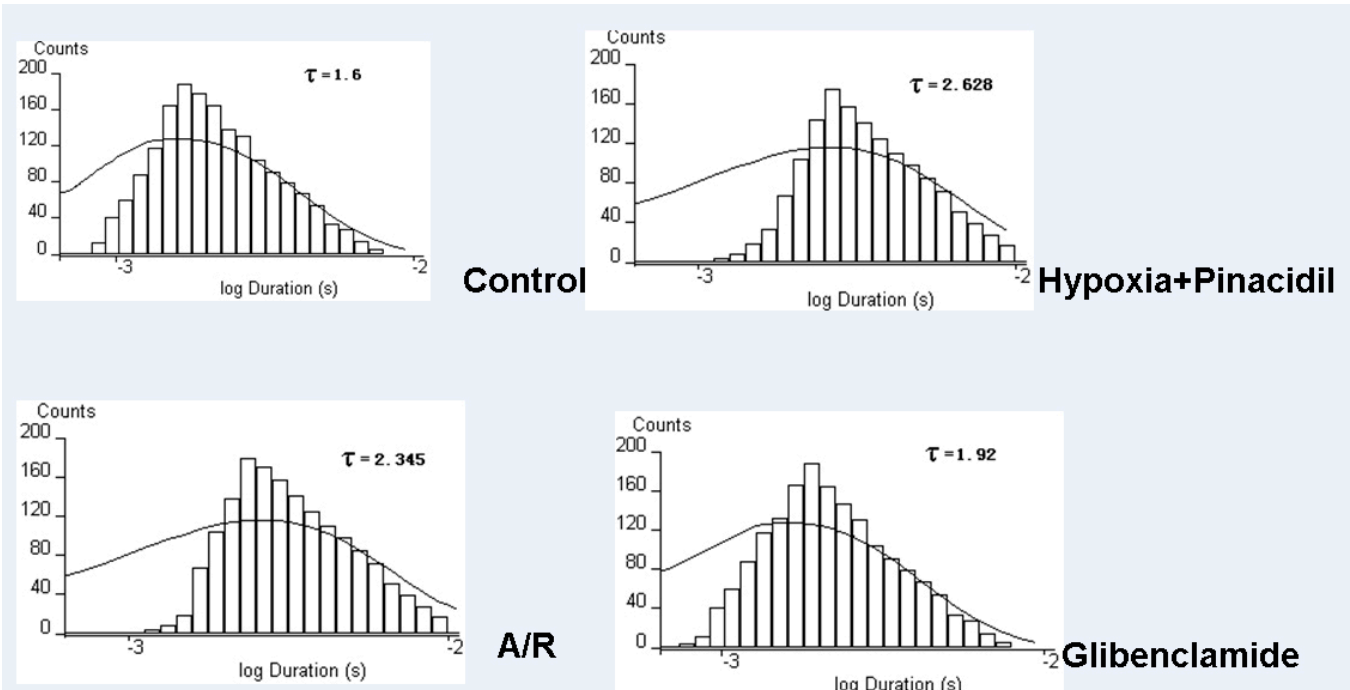

A/R

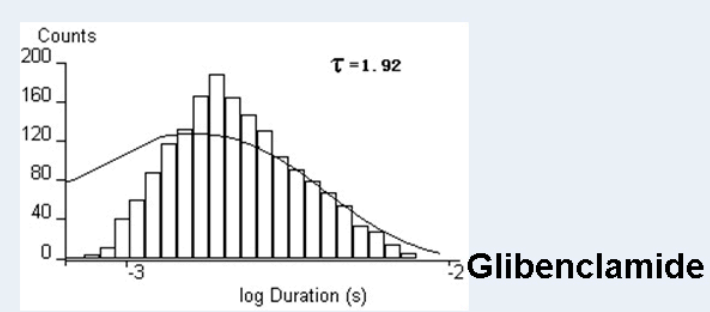

Figure 8. Open-time histograms of the four groups of $\mathrm{K}_{\text {ATP }}$ channels found in isolated rat ventricular myocytes. These effects of pinacidil were abolished by the $\mathrm{K}_{\mathrm{ATP}}$ channel blocker glibenclamide. Note that Po/Po-control with each [pinacidil] $\mathrm{i}$ was averaged from 6 different membrane patches $(\mathrm{N}=6)(\mathrm{P}<0.01)$. The Po values are listed as follows: control (1.6), pinacidil (2.628). Po value means time constant $(\tau)$, which is defined as the variable change with time of the exponential distribution. 


\section{DISCUSSION}

$\mathrm{K}_{\text {ATP }}$ channels are regulated by the ratio of intracellular ATP and ADP concentrations (Edwards and Weston, 1993). These channels were first discovered in cardiomyocytes and later found in various tissues, such as pancreatic $\beta$-cells, skeletal muscle, and vascular and nonvascular smooth muscle. The isolated hearts were perfused in the Langendorff apparatus, undergoing $30 \mathrm{~min}$ of global ischemia and $60 \mathrm{~min}$ of reperfusion. The recovery of cardiac function in the pinacidil group was enhanced $60 \mathrm{~min}$ after ischemia/reperfusion compared with that in the control group $(\mathrm{P}<0.05)$, indicating that pinacidil had a cardioprotective effect. In addition, cardiac function was restored better with pinacidil after 10 min of hypoxic exposure than with reperfusion after $10 \mathrm{~min}$ of hypoxic exposure $(\mathrm{P}<0.05)$. The recovery of cardiac function in the $\mathrm{A} / \mathrm{R}$ group was lower than that in the control group $(\mathrm{P}<0.05)$. All changes indicated definitively that a detrimental effect developed in the A/R group. These results suggest that proper transient hypoxia can protect rat hearts against ischemia/reperfusion injury, and this effect could be affected by the mode of transient hypoxic exposure. $\mathrm{K}_{\mathrm{ATP}}$ channels are blocked by glibenclamide and activated by pinacidil. This paper suggested that $\mathrm{K}_{\text {ATP }}$ channels were affected during anoxic preconditioning and had a final influence on reducing $\mathrm{A} / \mathrm{R}$-induced cardiac damage in rat hearts. Additionally, the effects of the activator of $\mathrm{K}_{\mathrm{ATP}}$ channels, pinacidil $(20 \mu \mathrm{M})$, and the blocker, glibenclamide $(10 \mu \mathrm{M})$, were investigated using ventricular myocytes that were isolated from rats in $\mathrm{K}-\mathrm{H}$ solution to be exposed to hypoxia. In this study, we showed whether and how the $\mathrm{K}_{\text {ATP }}$ channel opener pinacidil was involved in the protection that was afforded by A/R. Kinetic parameters such as HR, LVDP, LVSP, and $\pm d p /$ $d t_{\max }$ are different in myocardial A/R than in the control condition. During the whole period of reperfusion, the recovery of LVDP in rats after 10, 20, 30, and 60 min of pinacidil exposure was much better than that in the A/R group, and the recovery of the LVDP in the A/R group was worse than that in the control group $(\mathrm{P}<0.05)$. There was no significant difference in the LVSP among the control and pinacidil groups before ischemia/reperfusion. LVSP in rats after anoxic exposure was higher $(\mathrm{P}<0.01)$ during reperfusion than in the control and pinacidil groups. During reperfusion, the absolute values of $\pm \mathrm{LV} d p / d t_{\text {max }}$ were higher in pinacidil rats ( $\mathrm{P}$ $<0.01)$ than in $\mathrm{A} / \mathrm{R}$ rats. $\pm \mathrm{LV} d p / d t_{\max }$ values were significantly higher in the pinacidil group than in the other groups. The post-ischemic recoveries of the LVDP and $\pm d p / d t_{\max }$ in $\mathrm{A} / \mathrm{R}$ hearts were higher than those of the control group. Our study showed that the recovery of cardiac function was improved after ischemia/reperfusion developed in rat hearts after 10,30, and 60 min of pinacidil treatment, which confirmed the cardioprotective effect of pinacidil on rat heart. $\mathrm{K}_{\text {ATP }}$ channels are regulated by the ratio of intracellular ATP and ADP concentrations. These channels were first discovered in cardiomyocytes and were later found in various tissues, such as pancreatic $\beta$-cells, skeletal muscle, and vascular and nonvascular smooth muscle. $\mathrm{K}_{\text {ATP }}$ channels are blocked by glibenclamide and are activated by pinacidil. $\mathrm{K}_{\text {ATP }}$ channels are known to provide protection to myocytes.

In this study, we provide evidence that $\mathrm{K}_{\mathrm{ATP}}$ channels with potential biophysical properties are functionally expressed in isolated rat ventricular myocytes. The early changes in $\mathrm{Bax} / \mathrm{Bcl}-2$ and $\mathrm{FN}$ expression in ischemic myocardium following reperfusion in 24 rats were studied by histochemical, immunohistochemical, and image analysis techniques. The OD values of Bax/Bcl-2 and FN were significantly increased $60 \mathrm{~min}$ after reperfusion. Pinacidil postconditioning (PPC) restored the decreased the expression of Bcl-2 and FN in isolated 
hearts that were subjected to ischemia and reperfusion. Bax levels were not different among the groups. The data provide further evidence that apoptosis contributes independently to the infarct size after ischemia and reperfusion. Inhibiting the myocardial apoptotic processes by PPC may involve modulating the expression of the apoptotic proteins Bcl-2 and FN. PPC may be involved in the inhibition of both of these apoptotic proteins (Zhao and Vinten-Johansen, 2006; Murphy and Steenbergen, 2008). Our study suggests that PPC inhibits myocardial apoptosis after ischemia and reperfusion. We also evaluated whether the induced cardioprotection involves modulating the expression of the $\mathrm{Bax} / \mathrm{Bcl}-2$ and $\mathrm{FN}$ family proteins. Pinacidil may present its protective effect on $\mathrm{A} / \mathrm{R}$-injured cardiomyocytes through the likely mechanism of upregulating the expression of apoptosis protein Bcl-2 and Bax, and downregulating the expression of protein $\mathrm{FN}$. Our results suggest that $\mathrm{K}_{\mathrm{ATP}}$ channels may functionally be related to the activity of heart cells. $\mathrm{K}_{\text {ATP }}$ channels reduced the concentration of intracellular $\mathrm{Ca}^{2+}$, which contributed to maintain the plateau period of the action potential (Zhao and Vinten-Johansen, 2006; Ferdinandy et al., 2007). Thus, deficient $\mathrm{K}_{\text {ATP }}$ channels confer a greater susceptibility to calcium overload in $\mathrm{A} / \mathrm{R}$, impairing the contractile recovery under various conditions of high metabolic demand (Vinten-Johansen et al., 2005; Tsutsumi et al., 2007). The results of this paper suggested that $\mathrm{K}_{\text {АтP }}$ channels were affected during anoxic preconditioning and had a final influence on reducing $\mathrm{A} / \mathrm{R}$-induced cardiac damage in rat hearts.

Additionally, the effects of the activator of $\mathrm{K}_{\text {ATP }}$ channels, pinacidil $(20 \mu \mathrm{M})$, and the blocker, glibenclamide $(10 \mu \mathrm{M})$, were investigated using ventricular myocytes that were isolated from rats in Kerb solution to be exposed to hypoxic condition. These changes were more pronounced in the pinacidil groups. The administration of pinacidil protected rat ventricular myocytes under conditions of hypoxia-reperfusion, whereas glibenclamide abolished these changes. The objective of this study was to determine whether $\mathrm{K}_{\text {ATP }}$ channels confer cardioprotection from reperfusion. $\mathrm{K}_{\text {ATP }}$ channels would be expected to mitigate ischemicreperfusion injury. Ischemic postconditioning by pinacidil exerts a cardioprotective effect, which may contribute partly to the ultimate opening of $\mathrm{K}_{\text {ATP }}$ channels in acute myocardial A/R. Additionally, using a patch-clamp technique, we examined the single-channel electrophysiological properties of the $\mathrm{K}_{\text {ATP }}$ channels in isolated rat ventricular myocytes, including the mean open time and conductance value. Our results suggest that these properties of $\mathrm{K}_{\mathrm{ATP}}$ channels may functionally be related to the activity of heart cells. From an electrophysiological point of view, cardioprotection may involve changes in ion current. Because the action potential is the signal that regulates both the duration and frequency of myocardial contraction, its modifications affect the mechanical performance of the heart. In this study, we developed an effective animal model of pinacidil cardioprotection in rat hearts using transient hypoxia. Pinacidil was used in rat hearts immediately after hypoxia in our previous study and used before reperfusion in this study. The speculated reason for differences between the studies might be the initial time when pinacidil was applied. Pinacidil was used in rat hearts immediately after hypoxia in our previous study and used before reperfusion in the present study. In addition, some ion fluxes across the cell membrane require energy and therefore decreased contraction by shortening the action potential by opening the $\mathrm{K}_{\mathrm{ATP}}$ channels in anoxic cells; administering $\mathrm{K}_{\mathrm{ATP}}$ channel openers removed the calcium overload. The $\mathrm{K}_{\text {ATP }}$ channels reduced the concentration of intracellular $\mathrm{Ca}^{2+}$, which contributed to maintain the plateau period of the action potential. Thus, deficient $\mathrm{K}_{\text {ATP }}$ channels confer a greater susceptibility to calcium overload in $\mathrm{A} / \mathrm{R}$, impairing the contractile recovery under various conditions of high 
metabolic demand (Tawa et al., 2010). These changes were more pronounced in the pinacidil groups. The administration of pinacidil protected rat ventricular myocytes under conditions of hypoxia-reperfusion, whereas glibenclamide abolished these changes. The objective of this study was to determine whether $\mathrm{K}_{\text {ATP }}$ channels confer cardioprotection during reperfusion. This study showed that the recovery of cardiac function was better after 10, 30, and 60 min of pinacidil treatment than without treatment, which confirmed again the cardioprotective effect of pinacidil. Ischemic postconditioning by pinacidil exerts a cardioprotective effect (Mewton et al., 2010), which may contribute partly to the ultimate opening of $\mathrm{K}_{\mathrm{ATP}}$ channels in acute myocardial A/R. In summary, our research demonstrated that the mode of THR is a key factor in the effect of cardioprotection (Zhu et al., 2010). Nevertheless, cardioprotection may prevent serious complications (e.g., arrhythmias), slow the disease process, and improve the heart function enough to allow more demanding treatments (e.g., surgical interventions). This study examined $\mathrm{K}_{\mathrm{ATP}}$-handling mechanisms involved in cardioprotection that is induced by transient ischemia-reperfusion injury.

\section{REFERENCES}

Beguin PC, Joyeux-Faure M, Godin-Ribuot D, Levy P, et al. (2005). Acute intermittent hypoxia improves rat myocardium tolerance to ischemia. J. Appl. Physiol. 99: 1064-1069.

Edwards G and Weston AH (1993). The pharmacology of ATP-sensitive potassium channels. Annu. Rev. Pharmacol. Toxicol. 33: 597-637.

Ferdinandy P, Schulz R and Baxter GF (2007). Interaction of cardiovascular risk factors with myocardial ischemia/ reperfusion injury, preconditioning, and postconditioning. Pharmacol. Rev. 59: 418-458.

Gok S, Vural K, Sekuri C, Onur R, et al. (2006). Effects of the blockade of cardiac sarcolemmal ATP-sensitive potassium channels on arrhythmias and coronary flow in ischemia-reperfusion model in isolated rat hearts. Vascul. Pharmacol. 44: $197-205$.

Gumina RJ, O'Cochlain DF, Kurtz CE, Bast P, et al. (2007). KATP channel knockout worsens myocardial calcium stress load in vivo and impairs recovery in stunned heart. Am. J. Physiol. Heart Circ. Physiol. 292: 1706-1713.

Holmuhamedov EL, Wang L and Terzic A (1999). ATP-sensitive $\mathrm{K}^{+}$channel openers prevent $\mathrm{Ca}^{2+}$ overload in rat cardiac mitochondria. J. Physiol. 519: 347-360.

Mewton N, Ivanès F, Cour M and Ovize M (2010). Postconditioning: from experimental proof to clinical concept. Dis. Model. Mech. 3: 39-44.

Murphy E and Steenbergen C (2008). Mechanisms underlying acute protection from cardiac ischemia-reperfusion injury. Physiol. Rev. 88: 581-609.

Tawa M, Fukumoto T, Yamashita N, Ohkita M, et al. (2010). Postconditioning improves postischemic cardiac dysfunction independently of norepinephrine overflow after reperfusion in rat hearts: comparison with preconditioning. $J$. Cardiovasc. Pharmacol. 55: 6-13.

Tsutsumi YM, Yokoyama T, Horikawa Y, Roth DM, et al. (2007). Reactive oxygen species trigger ischemic and pharmacological postconditioning: in vivo and in vitro characterization. Life Sci. 81: 1223-1227.

Vanden Hoek T, Becker LB, Shao ZH, Li CQ, et al. (2000). Preconditioning in cardiomyocytes protects by attenuating oxidant stress at reperfusion. Circ. Res. 86: 541-548.

Vinten-Johansen J, Zhao ZQ, Zatta AJ, Kin H, et al. (2005). Postconditioning - A new link in nature's armor against myocardial ischemia-reperfusion injury. Basic Res. Cardiol. 100: 295-310.

Wang Y and Ashraf M (1999). Role of protein kinase C in mitochondrial KATP channel-mediated protection against $\mathrm{Ca}^{2+}$ overload injury in rat myocardium. Circ. Res. 84: 1156-1165.

Zhao ZQ and Vinten-Johansen J (2006). Postconditioning: reduction of reperfusion-induced injury. Cardiovasc. Res. 70: 200-211.

Zhou M, Tanaka O, Sekiguchi M, He HJ, et al. (2005). ATP-sensitive $\mathrm{K}^{+}$-channel subunits on the mitochondria and endoplasmic reticulum of rat cardiomyocytes. J. Histochem. Cytochem. 53: 1491-1500.

Zhu HF, Dong JW, Zhu WZ, Ding HL, et al. (2003). ATP-dependent potassium channels involved in the cardiac protection induced by intermittent hypoxia against ischemia/reperfusion injury. Life Sci. 73: 1275-1287.

Zhu HL, Qu SL and Xiao XZ (2010). Progress of clinical research on ischemic postconditioning. Zhonghua Xin. Xue Guan. Bing Za Zhi 38: 189-192. 